\title{
FIVE YEARS OF RESEARCH IN ABSOLUTE RADIATION THERMOMETRY AT CEM
}

\section{Пятилетних исследований в абсолютном радиационной термометрии в СЕМ}

\author{
J. M. Mantilla
}

Centro Español de Metrología, Tres Cantos, Spain

Telephone: +34 918074767. Fax:+34 918074807.e-mail: jmmantilla@cem.minetur.es.

\begin{abstract}
As part of the revision of the International System of Units (SI), the kelvin, unit of thermodynamic temperature, will be redefined by fixing the value of a value to the Boltzmann constant $k$, a definition broad enough to encompass any form of thermometry [1]. The evolving mise en pratique for the definition of the kelvin (MeP-K) [2] will, in its forthcoming edition, encourage the realisation and dissemination of the thermodynamic temperature, $T$, either directly (primary thermometry), or indirectly (relative primary thermometry) via fixed points with assigned reference thermodynamic temperatures.
\end{abstract}

Since 2011, Centro Español de Metrología (CEM), the Spanish NMI and Instituto de Óptica of Consejo Superior de Investigaciones Científicas (IO-CSIC), the Spanish Designated Institute for luminous intensity and luminous flux, have been working together in the absolute spectral responsivity calibration of standard radiation thermometers and filter radiometers for the dissemination of absolute radiation temperature.

This paper describes the different approaches followed, the instruments and facilities developed, the main achievements obtained and indicates the forthcoming work in this field.

Keywords: absolute radiation thermometry; radiance method; standard radiation thermometer, filter radiometer.

\section{Абстрактные}

B рамках пересмотра Международной системы единиц (SI), кельвин, единица термодинамической температуры, будут пересмотрены путем присвоения значения к постоянной Больцмана к, определение достаточно широким, чтобы охватить любую форму термометрии. Формирующийся mise en pratique для определения кельвина (MEP-K) [2] будет в своем предстоящем издании, поощрять реализацию и распространение термодинамической температуры, либо непосредственно (первичные термометрия), или косвенно (относительный первичные термометрия) с помощью фриксированных точек с заданными эталонными термодинамических температур.

Начиная с 2011 года, Centro Español де Metrologia (CEM), испанский NMI и Instituto de Óptica of Consejo Superior de Investigaciones Científicas (IO-CSIC), испанский Места институт силы света и светового потока, Совместно работают в абсолютной спектральной чувствительности калибровке из стандартного излучения термометры и фрильтр радиометр для распространения абсолютной температуры излучения.

В данной статье описываются различные подходы, инструменты и эксперимент разработанные, основные достижения, полученные и указывает на предстоящую работу в этой области.

Ключевые слова: абсолютное излучение термометрии; Метод сиянием; стандарт Пирометр, фильтр радиометр. 


\section{a. Statement of the problem}

The global measurement system, grounded in the international system of units (the SI), is the essential foundation for reliable measurement. Such a measurement system, is necessary for trade, manufacturing, sustaining and improving quality of life. it is expected that the General Conference on Weights and Measures (CGPM) will approve the most fundamental change to the SI system ever undertaken since its inception redefining the SI units in terms of fixed values of fundamental constants and forces the National Measurement Institutes (NMI's) to be prepared for these changes in order to be able to provide traceability to the next SI to their customers. This momentous change needs to be supported with research and documentation to ensure a successful and effective redefinition takes place [3]. In the particular case of thermometry, this change will be effected through developing primary thermometry methods that both challenge and supplant the defined scales.

\section{b. Analysis of the latest research and publications}

The latest more relevant research in the field of primary thermometry was EMRP's "Implementing the new kelvin" (InK) project [4]. In one of the work packages of this project, several NMI's across the world determined the thermodynamic temperatures to the points of inflection of the melting transition curves of the black body high temperature fixed points (HTFPs) of Re-C, Pt-C, Co-C and Cu by primary radiometry. Table 1 shows the calibration approach and the uncertainties achieved by each participating laboratory [5].

\begin{tabular}{lll}
\hline Laboratory & Calibration approach & $\boldsymbol{u} \mathbf{C u}-\boldsymbol{u}$ Re-C $(\boldsymbol{k}=\mathbf{1})$ \\
\hline NRC (Canada) & Power (monochromator source) & $0.10 \mathrm{~K}-0.42 \mathrm{~K}$ \\
NIST (USA) & Radiance (laser source) & $0.18 \mathrm{~K}-0.36 \mathrm{~K}$ \\
VNIIOFI (Russia) & Irradiance (monochromator source) & $0.09 \mathrm{~K}-0.29 \mathrm{~K}$ \\
PTB (Germany) & Irradiance (monochromator source) & $0.09 \mathrm{~K}-0.34 \mathrm{~K}$ \\
LNE/Cnam (France) & Radiance (laser source) & $0.07 \mathrm{~K}-0.28 \mathrm{~K}$ \\
CEM (Spain) & Radiance (monochromator source) & $0.17 \mathrm{~K}-0.57 \mathrm{~K}$ \\
NIM (China) & Hybrid (monochromator source) & $0.07 \mathrm{~K}-0.36 \mathrm{~K}$ \\
NMIA (Australia) & Iluminance (broadband source) & $-----0.33 \mathrm{~K}$ \\
NMIJ (Japan) & Radiance (supercontinuum source) & $0.13 \mathrm{~K}-0.52 \mathrm{~K}$ \\
\hline
\end{tabular}

Table 1: Approaches and uncertainties achieved by the different InK project participants.

\section{c. Determination of the way of solving the general problem}

Depending on local requirements and constraints, each laboratory selects the best calibration method of primary spectral-band radiometers to measure the absolute spectral radiance (units $\mathrm{W} \mathrm{m}^{-2} \mathrm{sr}^{-1} \mathrm{~nm}^{-1}$ ) of a blackbody cavity [5]. Planck's law is used to convert radiance to temperature. All calibration methods rely on an optical power measurement with a cryogenic electrical substitution radiometer, a monochromatic optical radiation source and a defining geometry of two parallel, circular, collinear apertures of known physical dimensions and separation. The methods differ only in the location of the geometry in the calibration chain. The four most relevant of these methods are:

- Power: the power responsivity is determined by calibration against a source that underfills the radiometer. For this method the uniformity of the detector is very important.

- Irradiance: the radiometer's and transfer standard's entrances are delimitated by two different precision apertures and overfilled by an uniform irradiance.

- Hybrid: applied to small blackbody cavities, introduces a single lens. The calibration is usually performed "in parts", with the irradiance responsivity of the filter radiometer and the transmittance of the lens determined separately, an additional aperture is added to the lens to form the geometric system for radiance measurements.

- Radiance: the calibration of such a system is by comparison with a source of known radiance. The instrument can then determine the blackbody radiance directly. The configuration of the radiometer in this method is the same in calibration as in use. 


\section{d. Statement of the task, formulation of the aims of the paper}

CEM IO-CSIC chose to follow radiance method because it was planned to calibrate in first place a commercial radiation thermometer (KE LP2) and this is the only method can be used for a device with such a complex optical system. It was also planed to develop non commercial radiation thermometers, called filter radiometers, specifically designed for this project that could have been designed for being calibrated in irradiance mode or the hybrid method, but a series of inconveniences and lacks made discard these methods such as the difficulty on placing optical components in front of high temperature furnaces and refrigerate them properly or the lack of big aperture black body sources suitable for being measured in the only high temperature furnace CEM owns. Hence, it was decided to calibrate filter radiometers with the radiance method too.

A radiation thermometer calibrated in absolute spectral radiance responsivity, $S_{\mathrm{RT}}^{L}(\lambda)$, can be used to calculate the thermodynamic temperature, $T$, of a black body from equation (1) where $I_{p h}$ is the photocurrent measured and $L(\lambda, T)$ is the spectral radiance given by Planck's law at temperature $T$ [6]:

$$
I_{p h}=\int S_{\mathrm{RT}}^{L}(\lambda) L(\lambda, T) d \lambda
$$

\section{e. Presentation of the main research material with explanation of the obtained scientific results}

The first attempt of measuring thermodynamic temperatures traceable to the primary cryogenic radiometer of IO-CSIC, was the absolute spectral responsivity calibration of CEM's KE-LP2 standard radiation thermometer in the range of $650 \mathrm{~nm}$ using the lampmonochromator based facilities described in [7]. The main uncertainty components associated to this calibration were related to the geometric factor determination and with the stability of the lamps used as radiation sources. Laser sources are more stable than lamps but they are not suitable for calibrating the LP2 because their coherent emission produce interference fringes on the radiometer. Therefore, it was decided to develop a non commercial filter radiometer able to be calibrated in a lased based facility and a radiancemeter with improved features for the low uncertainty determination of the geometric factor.

CEM radiancemeter is a compact, geometrically and spectrally stable, repetitive device. It has a housing for one of the apertures and its trap detector would has a specific housing at the front for the $3 \mathrm{~mm}$ aperture. The distance between apertures is calibrated before and after radiometric calibrations to ensure the distance remains stable. It also has a water jacket to maintain the detector and apertures near $20.5^{\circ} \mathrm{C}$, the temperature at which dimensional calibrations are performed.

The first CEM IO CSIC filter radiometer, the Filter Radiometer 1 (FiRa1), had a simple design consisting on a focusing lens, a field stop, a collimating lens, a Lyot stop, a $650 \mathrm{~nm}$ inference filter, a photodetector and a preamplifier. It was mounted on a cylinder with a refrigeration water jacket to reduce drifts caused by the sensitivity of the interference filter, the detector and the preamplifier to temperature. The interference filter disposition respect to the detector is non parallel in order to avoid interference fringes caused by coherent light sources. Unfortunately, an error was found in FiRa1's design that made discard it: the target diameter size of the radiometer is $4.5 \mathrm{~mm}, 1.5 \mathrm{~mm}$ bigger than the typical $3 \mathrm{~mm}$ cavity diameter of HTFPs.

Accordingly, it was decided to develop a new filter radiometer FiRa2, exclusively conceived for being calibrated in laser based facilities and to meet the needs for measuring HTFPs. The aim was to build a robust, simple and low budget instrument focused on improving geometry stability, size of source effect, linearity and drift. 
Figure 1 shows the final CAD model from which the filter radiometer was developed. Drifts were observed in the temperature measurement of Re-C HTFP with FiRa2 between days. Unfortunately, there was not enough time to perform changes on its configuration in order to improve stability and recalibrate the instrument prior to InK WP1 measurements. This forced to perform InK measurements with the LP2, although it had higher uncertainties than FiRa2.

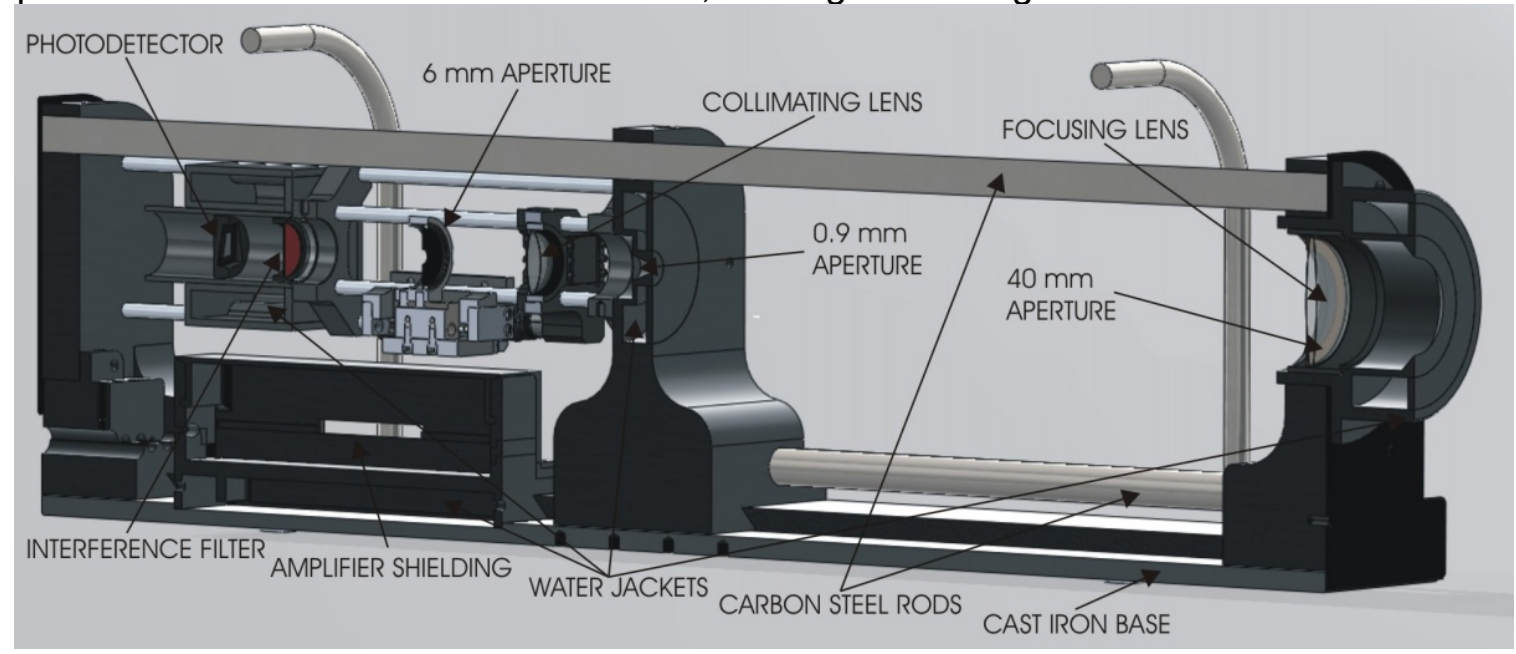

Fig 1: CEM FiRa2 filter radiometer scheme

The absolute spectral radiance responsivity calibration of FiRa1 and FiRa2 was performed in first place at IO-CSIC in a laser-based facility [8]. Both radiometers were calibrated in the wavelength of $650 \mathrm{~nm}$. A wideband source was required for the calibration from $600 \mathrm{~nm}$ to $700 \mathrm{~nm}$. The apparatus used for this purpose was a Coherent ${ }^{\circledR} 599$ Standing Wave Dye Laser cavity.

To avoid drifts during transport, it was decided to calibrate the radiometers at CEM [9], where temperature measurements take place, starting with a laser based experiment using a $\mathrm{CW}$ Coherent ${ }^{\circledR}$ diode laser OBIS model 648 in combination with a relative spectral calibration.

Afterwards, a new absolute radiance responsivity calibration facility based in a monochromator with a supercontinuum (SC) laser as radiation source, shown in Fig 2, has been developed for the calibration of the KE-LP2, FiRa2 and a commercial KE-LP4, all of them at central wavelengths of $650 \mathrm{~nm}$. In both systems a diffuser plate is placed before the entrance port of the integrating sphere to suppress speckle. SC laser emission is not as coherent as conventional lasers, interference fringes were neither observed in KE-LP2 nor in KE-LP4.

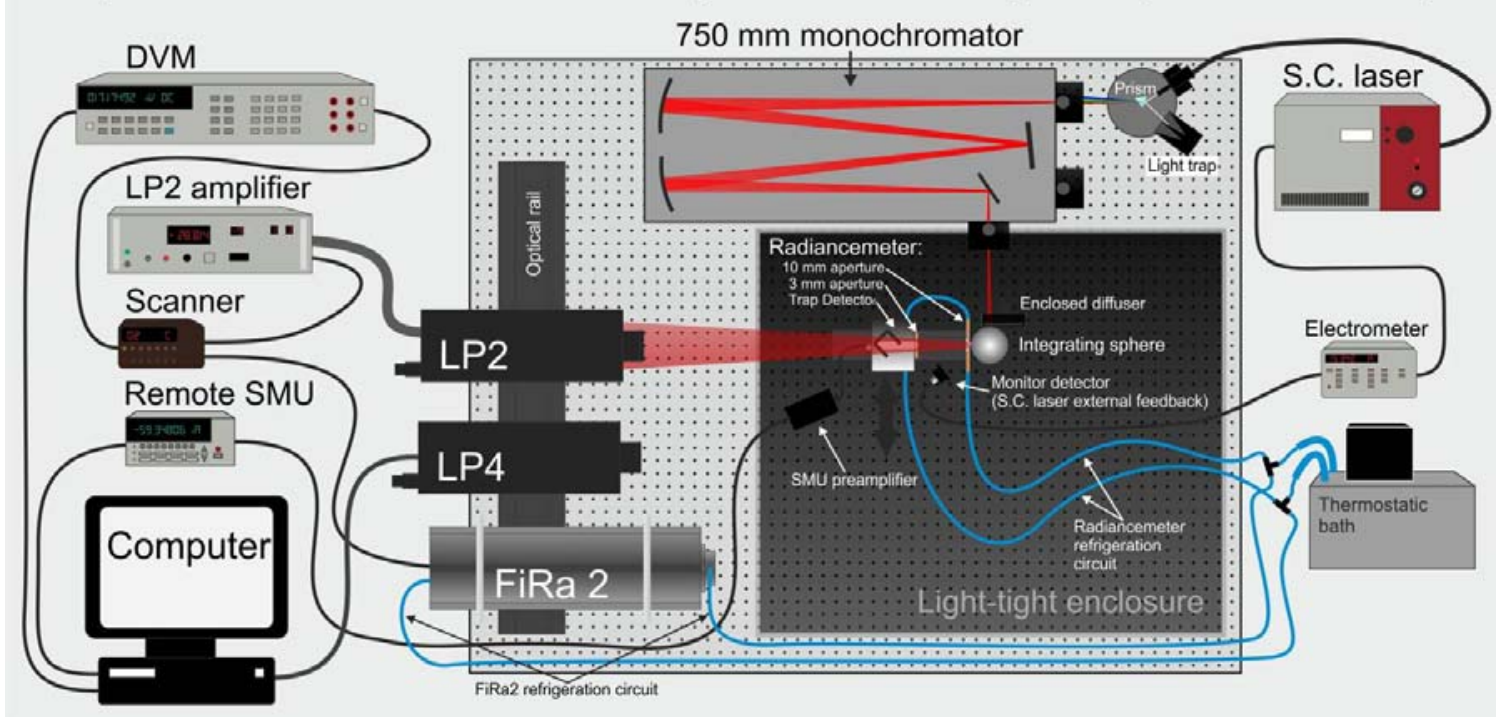

Fig 2 Supercontinuum laser based absolute spectral radiance responsivity calibration facility. 
Table 2 summarizes the uncertainties of the fixed point thermodynamic temperature measurements obtained from the different calibration systems of the LP2, LP4 and FiRa2.

\begin{tabular}{lcc}
\hline \multicolumn{1}{c}{ Calibration system (650 $\mathbf{n m})$} & Instruments calibrated & $\boldsymbol{u} \mathbf{C u}-\boldsymbol{u} \mathbf{R e}-\mathbf{C}(\boldsymbol{k}=\mathbf{1})$ \\
\hline Dye laser (IO) & FiRa2 & $0.17 \mathrm{~K}-0.71 \mathrm{~K}$ \\
Lamp-Monochromator (IO) & FiRa2, LP2, LP4 & $0.15 \mathrm{~K}-0.56 \mathrm{~K}$ \\
Diode laser CEM) & FiRa2 & $0.12 \mathrm{~K}-0.49 \mathrm{~K}$ \\
SC laser -Monochromator (CEM) & FiRa2, LP2, LP4 & $0.11 \mathrm{~K}-0.42 \mathrm{~K}$ \\
\hline
\end{tabular}

Table 2 Standard uncertainties of fixed point measurements from the different facilities.

\section{f. Conclusions from research data and the prospect to future investigations in this direction.}

Since 2011 CEM, in collaboration with IO-CSIC, has been developing absolute spectral responsivity calibration facilities based in different light sources: incandescent and discharge lamps, a dye laser, a diode laser and a supercontinuum laser.

Two standard radiation thermometers and two filter radiometers developed at CEM, all of them working in nominal wavelengths around $650 \mathrm{~nm}$, have been calibrated in those facilities intending to obtain lower uncertainties in the measurement of thermodynamic temperatures than the uncertainties provided by the International Temperature Scale of 1990 (ITS-90) being the monochromator-SC facility the best approach for that purpose.

The good agreement respect to other institutes suggests that spectroradiometric thermometry techniques are sufficiently mature at CEM to allow the direct realization of thermodynamic temperature above $1234 \mathrm{~K}$. However, systems must be implemented in the future in order to obtain lower uncertainties similar than the best achieved by other NMIs.

Also, three different methods have been used for the absolute calibration of FiRa2 filter radiometer giving compatible results well below the calibration uncertainties. However, FIRA2 drifts $0,2{ }^{\circ} \mathrm{C}$ at $\mathrm{Co}-\mathrm{C}$ fixed point after measuring Re-C. The study and improvement of FiRa2's behaviour has been planned for the future.

At present, CEM and IO-CSIC are participating in the InK 2 project which aims determine low uncertainty values of the differences between the thermodynamic temperature $(T)$ and the temperature defined fy the ITS-90 $\left(T_{90}\right)$ in the range from $\sim 430 \mathrm{~K}$ to $\sim 1358 \mathrm{~K}$. Silicon based LP2 and LP4 will be calibrated at $950 \mathrm{~nm}$ and $900 \mathrm{~nm}$ respectively and a new KE-LP5 with an InGaAs detector will be calibrated at $1.5 \mu \mathrm{m}$ against a new InGaAs transfer standard. Irradiance method will be investigated within the frame of this project given that CEM has large black body sources in this temperature range.

\section{References}

[1] Fellmuth, B. et al. Phil. Trans. R. Soc. A (2016) 374: 20150037

[2] Ripple, D. C., Davis, R., Fellmuth, B, Fischer, J., Machin, G. et al Int. J. Thermophys. (2010) 31:1795-1808

[3] Publishable Summary for EURAMET 15SIB02 InK 2 Implementing the new kelvin 2

[4] Machin, G., Engert, J., Gavioso, R. et al. Measurement: Journal of the International Measurement Confederation (2016) 94. 149-156

[5] Woolliams, E. R. et al. Phil. Trans. R. Soc. A (2016) 374: 20150044

[6]Document CCT-10/13

[7] Mantilla, J. M., Hernanz, M. L., Campos, J., Martín, M. J., Pons, A. and del Campo, D. Int. J. Thermophys. (2014) 35:493-503

[8] Mantilla, J. M., Martin, M. J., Hernanz, M. L., Pons, A., Campos, J. and del Campo, D. Proceedings NEWRAD'14, Helsinki (Finland) (2014) 265-266

[9] Martín, M. J., Mantilla, J. M., del Campo, D., Hernanz, M. L., Pons, A. and Campos, J. Subbmitted to the Int. J. Thermophys. Tempmeko 2016 Special Issue 